\title{
RELAÇÕES CIDADE-CAMPO E URBANO-RURAIS: REAPRESENTANDO AS URBANIDADES NO RURAL COMO ELEMENTOS CONSTITUTIVOS DO ESPAÇO EM METROPOLIZAÇÃO
}

\section{João Rua*}

Pontifícia Universidade Católica do Rio de Janeiro

Resumo: 0 artigo procura analisar as relações urbano-rurais integradas à metropolização do espaço, compreendida como o processo espacial dominante atualmente. As constantes transformações nas relações entre espaço-sociedade tornaram as tradicionais divisões rural-urbanas cada vez mais indistintas, embora ainda permaneçam significantes particularidades e singularidades nesses subespaços. Utilizamos a abordagem dialética materialista para compreender os fenômenos acima a partir da noção de totalidade. Essa abordagem nos leva à noção de "urbanidades em áreas rurais" considerando-as como manifestações de territórios híbridos, nos quais o urbano e o rural se entrelaçam.

Palavras chave: Relações cidade-campo; relações urbano-rurais; urbanidades no rural; metropolização do espaço

\section{CITY-COUNTRYSIDE AND URBAN-RURAL RELATIONS: REINTRODUCING URBANITIES IN RURAL AREAS AS CONSTITUTIVE ELEMENTS OF SPACE IN METROPOLIZATION}

Abstract: The paper focuses the urban-rural relations integrated by the metropolization of space seen as the dominant spatial process nowadays. The changing relationship between space and society has rendered traditional divisions rural-urban increasingly indistinct although significant particularities and singularities still remain. We use the materialistic dialectical approach in order to understand the above phenomena based on the notion of totality. This approach suggests that another dialectic may lead to the idea of "urbanities in rural areas" considering this ones as manifestations of hybrid territories, in which the urban and rural intertwine.

Key words: City-countryside relations; urban-rural relations; urbanities in rural areas; metropolization of space.

RELACIONES CIUDAD-CAMPO Y URBANO-RURALES: REPRESENTANDO LAS URBANIDADES EN LO RURAL COMO ELEMENTOS CONSTITUTIVOS DEL ESPACIO EN LA METROPOLIZACIÓN Resumen: El artículo busca analizar las relaciones urbano-rurales integradas con la metropolización del espacio, entendido como el proceso espacial actualmente dominante. Los constantes cambios en las relaciones entre el espacio y sociedad han hecho que las tradicionales divisiones rural-urbano sean cada vez más indistintas, aunque aún subsisten importantes particularidades y singularidades en estos subespacios. Utilizamos el enfoque dialéctico materialista para comprender los fenómenos anteriores desde la noción de totalidad. Este enfoque nos lleva a la noción de "urbanidades en áreas rurales" considerándolas como manifestaciones de territorios híbridos, en los que lo urbano y lo rural se entrelazan.

Palabras-llave: Relaciones ciudad-campo; relaciones urbano-rurales; urbanidades en lo rural; metropolización del espacio. 
Introdução

Este artigo ${ }^{1}$ retoma ideias apresentadas em outros trabalhos do próprio autor, além de explicitar outras formulações ainda não expostas anteriormente, e tem como objetivo (re)apresentar uma análise sobre as novas relações urbano-rurais, manifestadas como urbanidades no rural, integradas à metropolização como o processo espacial dominante nos dias atuais, procurando apontar algumas maneiras de aproximação com as múltiplas realidades que constituem o espaço de vida.

Torna-se necessário ressaltar a opção, efetuada neste trabalho, por uma perspectiva analítica pautada pela crítica à lógica capitalista de organização e produção do espaço, com isso reconhecendo que outras lógicas são possíveis e devem ser esclarecidas já que são apoiadas em distintas cosmovisões, as quais representam maneiras de se contrapor à espacialidade capitalista hegemônica² ${ }^{2}$

Para problematizar, dentro dessa lógica hegemônica, as novas relações urbano-rurais em um espaço de metropolização (e do espaço rural integrado à lógica da globalização), utilizaremos como base para a análise efetuada, as seguintes perspectivas: a) o espaço como totalidade, a qual nunca se realiza, mas nos indica uma escala geral da lógica predominante na organização do espaço contemporâneo - podendo falar-se de totalidade em totalização, como nos indica Milton Santos (1996), ao destacar a importância do movimento expresso neste último termo; b) a necessidade da observação das leituras

$1 \mathrm{Em}$ primeiro lugar agradeço a Joana Cruz de Simoni, meus "olhos" neste trabalho, cuja paciência nas intermináveis leituras do texto e nas tessituras dos retalhos por mim ditados, constitui-se em verdadeira artesã deste trabalho. Desejo agradecer, também, ao querido amigo Rogério Haesbaert pela carinhosa e acurada leitura crítica, com algumas correções de rumo, as quais muito aprimoraram este trabalho. É claro que as imprecisões que persistirem são de total responsabilidade deste autor.

2 Ao nos posicionarmos criticamente frente à espacialidade capitalista, fazemo-lo a partir dos parâmetros euro-americanocêntricos que lhe dão suporte Será uma espécie de crítica "por dentro", isto é, buscando compreender as relações urbano-rurais como evidências da própria evolução do capitalismo, utilizando uma narrativa histórica pautada na ideia de uma possível superação desse verdadeiro sistema civilizatório o qual, ao atravessar as múltiplas dimensões da vida, ultrapassa a ideia de modo de produção, conforme originalmente definido. Entretanto, outras histórias, epistemes, narrativas, culturas coexistem É necessário sempre valorizar essas outras cosmovisões (ameríndias, africanas, asiáticas) pois delas têm advindo importantes manifestações em forma de insurgências de matiz variado, dando origem a territorialidades seguindo parâmetros distintos daqueles hegemônicos no capitalismo, principalmente no que diz respeito às relações sociedade-natureza, constituindo-se em outros meios geográficos. Essas outras perspectivas são desenvolvidas pelas abordagens pós-coloniais, decoloniais, anti-coloniais e descoloniais (conforme o autor), as quais nos apontam o espacco experienciado como territórios constituídos na luta pelo direito a sustentar identidades envolvidas em relações de poder bastante assimétricas, como acontece em muitas regiões da América Latina. O lugar, constituído como espaço da vida em sua cotidianidade, torna-se, também, um lugar de luta por garantia desse pertencimento, não apenas simbólico, mas como elemento concreto de suporte de identidades, formulando bases para a existência de outras geografias. Nelas existem/existiriam que tipos de relações cidade-campo? Há/haveria relações urbano-rurais no sentido totalizador observado no espaço capitalista? Como se apresenta/apresentaria uma espacialidade em moldes não capitalistas ou, até mesmo, pós-capitalistas, caso tal possibilidade se apresente? São perguntas, desafios e constatações que devem participar do arcabouço crítico à espacialidade até agora hegemônica. Pensamos ser importante esta nota por apontar possibilidades analíticas não incluídas neste trabalho, embora não desconhecidas ou não valorizadas. particulares e singulares realizadas pelos sujeitos nos lugares rurais, as quais se adequam ou resistem àquela lógica geral de organização, explicitando a multiplicidade do real; c) a ação multiescalar ${ }^{3}$ inerente ao processo de (re)produção do espaço, levada a cabo pelos múltiplos sujeitos (Estado, empresas, grandes e pequenos proprietários, não proprietários e trabalhadores rurais...) que se cruzam nas distintas relações de poder.

\section{Relações urbano-rurais integradas a um espaço em metropolização}

Refletir sobre conceitos de tão denso significado como cidade, campo, urbano, rural, urbanidades e ruralidades e metropolização do espaço coloca-nos em busca de um necessário rigor teórico com o qual sempre devemos estar ocupados ao considerar a historicidade e a contextualização geográfica de cada conceito. Cidade e campo atravessam a história e as sucessivas divisões sociais e territoriais do trabalho que neles vão se realizando. Por isso deve-se lembrar dos sujeitos sociais que conduzem essas formas espaciais e em que momento se realizam. Na antiguidade, no período medieval ou na modernidade, na cidade e no campo se elaboram distintas espacialidades que deixam marcas em dicotomias que até hoje se mantêm.

Como ignorar a importância das revoltas camponesas do final da idade média como elementos fundantes, não só de novas divisões territoriais do trabalho, mas também, como determinantes para o papel que a cidade e o urbano vão desempenhar na modernidade? Como não pensar a complexificação das classes sociais pósrevoluções políticas e na revolução industrial como elementos importantes no jogo de forças que se projeta no espaço da industrialização?

No último século e meio, a intensa produção e a densa circulação acionadas pela industrialização vão, a partir dos países centrais e um pouco por todo o mundo, promovendo uma crescente integração espacial na qual a cidade ganha novos significados. Pode-se falar em urbano e rural como processos integrados à lógica industrial e às novas maneiras como o capitalismo (re) produz o espaço por ele hegemonizado. Portanto, ao se considerar o espaço como totalidade aberta (em totalização) pode-se perceber o urbano e o rural como

3 Seguindo as formulações de Lencioni (2008), consideramos multiescalar e multiescalaridade as abordagens que nos conduzem a uma análise a partir da escala topológica (e não apenas topográfica), a qual considera, principalmente, os fluxos imateriais que reposicionam a distância numa lógica virtual (e não apenas métrica), modificando a noção do longe e do perto, ao aproximar lugares distantes e distanciar lugares próximos. Em nosso trabalho explicitamos tal abordagem quando se apresenta a multiplicidade como elemento-chave para a compreensão do rural contemporâneo, no qual as escalas e as relações se elaboram entre o local e a cidade e entre o local e as organizações globais. Podemos tomar como exemplo, o caso de redes globais de hospedagem, como o Airbnb, presente em localidades rurais (conforme nos demonstra Simoni, 2019). 
subtotalidades distintas na densidade, na composição e na raridade dos elementos que os compõem enquanto espaço ${ }^{4}$. A urbanidade estará ligada a comportamentos dos moradores da cidade e vai sendo pouco a pouco difundida pelo espaço (urbano e rural) como outras racionalidades, as quais permearão os modos de vida e as espacialidades que os sustentam, mesmo que se mantenham particularidades (e leituras particulares do processo geral de urbanização) e singularidades (jogos locais que explicitam as maneiras como os sujeitos sociais interagem submetendo-se, insurgindo-se ou adaptando o sentido homogeneizador da lógicacapitalista hegemônica). Ou então, como escreveu Haesbaert (1999, p. 24), "o aviltamento das desigualdades pelo capitalismo global altamente seletivo e, portanto, excludente; (...) o reafirmar das diferenças por movimentos sociais baseados no resgate ou reconstrução de identidades (religiosas, étnicas, nacionais etc.)", e urbanos e rurais, acrescentamos nós. Podemos relembrar que essas duas perspectivas (capitalismo excludente e reconstrução das identidades), além de permear todo nosso trabalho estarão profundamente atravessadas pelas questões de raça e gênero, além daquela das classes sociais.

Esse processo (as relações urbano-rurais e a produção de desigualdades e diferenças no espaço pelo capitalismo) pode ser percebido e analisado em inúmeras perspectivas. Em algumas análises priorizam-se os números, as densidades, as percentagens relacionadas à produção agrícola, aos sistemas técnicos de produção, aos tipos de solos e às unidades administrativas em que tal produção se realiza. Tudo isso é relevante, mas torna-se insuficiente ao tomarmos o espaço como uma totalidade ${ }^{5}$ em movimento e ao enfatizarmos 0 papel político dos sujeitos que dão sentido às práticas espaciais. Por totalidade compreende-se que a análise da realidade não se dá a partir da soma das partes, e devese encará-la em relação a outras totalidades, igualmente abertas e em permanente desdobramentos na análise efetuada. Assim, essa ideia - de totalidade -, em nosso trabalho, assenta-se nas contribuições de Henri Lefebvre

4 Reconhecemos a importância das definições de rural e urbano efetuadas pelos órgãos oficiais de estatística, no caso brasileiro, e a preocupação em atualizar tais definições. A sua importância é inegável quando se procura trabalhar com dados comparativos - principalmente na escala municipal. Entretanto é preciso estar atentos à tendência de isolar cada unidade administrativa do conjunto do qual fazem parte e de reconhecer que se enfatiza apenas uma das múltiplas dimensões espaciais (como se constituíssem um container de variáveis). Deve ser destacada novamente a permanente tentativa de redefinição para aqueles conceitos.

$5 \mathrm{~A}$ noção de totalidade apresenta muitas origens no conhecimento científico na modernidade ocidental. Utilizamos Henri Lefebvre e Milton Santos como autores que nos permitem aproximações ao conceito de espaço compreendido como totalidade. Elucidativa leitura a respeito da noção de totalidade no pensamento de Henri Lefebvre (o qual pode ser posto em diálogo com os outros dois autores citados) é apresentada por Lencioni (2018) quando explica essa noção integrada à abordagem triádica do autor francês. Doreen Massey, ao criticar a noção de totalidade na visão estruturalista - um sistema fechado que "reduz o espaço (...) à esfera causal fechada do nada-fazer, que o priva de todo potencial político" (MASSEY, 2008, p. 70). Essa autora dá suporte à ideia de totalidade sempre aberta a novas interações que neste trabalho utilizamos. e Milton Santos, principalmente, e Doreen Massey, ao tratar de uma totalidade aberta, nunca completada aqui denominada totalidade-espaço. Ao colocar esses três autores em diálogo reconhecemos o valor da crítica que a última faz à noção de totalidade fechada. Desse modo, percebe-se o espaço, além da maneira explicitada por Lefebvre (2008) - produto, meio e condição para a vida humana -, como uma abertura radical, heterogênea e esfera da possibilidade de existência da multiplicidade, tal como preconizado por Massey (2008).

Aí já se observa o movimento teórico-conceitual que marcará as reflexões efetuadas neste artigo: por um lado se perceberá uma influência de Marx e de autores por ele influenciados; por outro, serão notadas as referências a abordagens pós-estruturalistas. Totalidade e diferença estarão em diálogo permanente mesmo que isso apareça como uma certa composição eclética, a qual pode desafiar a busca do rigor teórico aludida acima.

Apoiados em Lencioni (2018) quando cita o pensamento de Henri Lefebvre, pode ler-se que: "a análise deve distinguir, mas não separar os momentos de um todo (...) A abstração necessária para os distinguir não deve os isolar, pelo contrário, deve revelar as contradições que se desenvolvem historicamente entre eles". A essa reflexão se voltará quando se analisarem algumas das dimensões do espaço propostas neste trabalho e os elementos que podem constituí-las.

Assim, se quer destacar que podemos tomar uma parte dessa totalidade como foco de investigação - por exemplo, ao tratar da presença de indústrias ligadas ou não à produção agrícola. Ao analisar esse elemento/ parte da totalidade devemos estabelecer as interações possíveis com outros elementos/partes sempre com a preocupação de pensar na totalidade-espaço. Seria necessário integrar o modelo de industrialização brasileira, a desconcentração industrial, o mercado de trabalho e a sua mobilidade urbano-rural e rural-urbana, o padrão técnico e seus efeitos na poluição atmosférica e hídrica, por exemplo. Então, a totalidade-espaço nunca poderá estar fechada (completa), pois, a cada momento novos elementos surgem para serem incorporados. Esse é o sentido geral que se dá, aqui, à ideia de totalidade, sempre aberta a novas interações - o que nos reforça a necessidade e colocar em diálogo os quatro autores acima referidos.

Para muitos geógrafos o espaço ainda não é assim percebido (como totalidade aberta, em movimento), já que, muitas vezes, continuam a trabalhar com o espaço geométrico, delimitado, pré-determinado e preso a escalas que o enclausuram. Perde-se, com isso, a perspectiva de considerá-lo como integrador da constituição de subjetividades políticas (conforme nos 
ensina Massey, 2004).

Parece cada vez mais necessário romper os estereótipos, as dicotomias e as representações, que obscurecem mais do que clarificam a dinâmica da produção do espaço no mundo contemporâneo e como a ciência geográfica pode explicá-la. A distinção cidadecampo, rural-urbano tem sido considerada a partir de uma dicotomização pautada no espaço como absoluto, com critérios baseados, sobretudo, na malha políticoadministrativa, no caso brasileiro. A dicotomia apontada acaba por superenfatizar (e, portanto, estereotipar) as diferenças entre rural e urbano, ao mesmo tempo em que camufla a diversidade presente nos espaços rurais, ao subenfatizá-la - ofuscando a multiplicidade dos lugares e dos sujeitos rurais.

Para escapar dessa dicotomização, optou-se pelo estudo das urbanidades no rural (que serão explicadas na próxima seção do texto), cuja abordagem permite a recomposição da totalidade do espaço (urbano + rural), o que não tem sido priorizado por outras perspectivas. Além disso, visa a resgatar a multidimensionalidade do espaço ${ }^{6}$ e nos colocar frente às contradições que a espacialidade contemporânea explicita - para a cidade e para o campo; para o(s) urbano(s) e para o(s) rural(is). Contribui, também, para o destaque (considerado essencial) da multi/transescalaridade dos processos espaciais, "necessária para a consideração da totalidadeespaço, integrando os moradores das localidades rurais, das cidades médias e das metrópoles a racionalidades hegemônicas da modernidade, compondo, com isso, novas imagens e representações do urbano e do rural" (RUA, 2019, p. 294).

Tentando romper com a ideia de rural como homogêneo, o que, como vimos, não destaca as distintas e múltiplas conexões resultantes da hibridização entre urbanidades e ruralidades, mesmo que se estabelecendo relações assimétricas, nas quais as primeiras se impõem. Urbanidades no plural já pretendem explicitar a abertura radical, a heterogeneidade e a multiplicidade anunciadas por Massey (2008). Logo, um novo desafio fica exposto: como compreender tal multiplicidade nos rurais resultantes de sucessivas e simultâneas desigualizações promovidas pela lógica capitalista hoje em dia planetária - e portadora da racionalidade urbana (LEFEBVRE, 1978), sem que signifique uma total

6 Ao se referir à multidimensionalidade do espaço, consideram-se as dimensões do físico-natural, o econômico, o social, o cultural, o ideológico, o institucional e o pessoal ligados ao cotidiano, de acordo com Milton Santos. Neste trabalho explicita-se essa multidimensionalidade integrando-a à ideia de totalidadeespaço. A perspectiva multidimensional poderia constituir-se em base analítica das partes componentes da totalidade-espaço. Cada parte/dimensão podendo ser decomposta numa série de elementos (por nós denominados indicadores em alguns trabalhos) investigados per se ou constitutivos de um conjunto, permitindo, assim, múltiplas interações. A preocupação de manter a totalidade como horizonte analítico deve estar sempre presente. homogeneização (difusão do valor de troca)? Como lidar com as diferenças resultantes das leituras particulares e singulares dos processos até aqui elencados? Haesbaert (1999, p. 24) escreve que a diversidade territorial se manifesta sob duas grandes formas:

- a produção de particularidades, do desigual (diferenças de grau), que vincula os espaços em distintas escalas;

- a produção de singularidades, do específico (diferenças de natureza), em geral mas não exclusivamente de base local e sem correlação obrigatória com realidades geográficas em outras escalas

Embora essa reflexão do autor tenha sido efetuada há muito tempo, ela ainda permanece válida quando nos chama atenção para a diferença de grau e de natureza, como vimos. Entretanto, torna-se necessário retomar as importantes contribuições desse autor ao enriquecer o conceito de multi/transescalaridade e evidenciar que, cada vez mais, se torna rara a existência de singularidades que não estejam a elas integradas.

Para nós, em acordo com o autor supracitado, desigualdade é produzida por processos de hierarquização, muitas vezes (mas nem sempre) expressos nas classes sociais e que se constituem em múltiplas (e desigualizadoras) escalaridades. A diferença de natureza pode ser expressa pelas singularidades do lugar (com algum alcance escalar) perpassadas pelas relações de gênero, raça, etnia, religião, etc., as quais vão demarcar "fronteiras" muito tênues frente às hierarquizações impostas pela propriedade privada, por exemplo. Queremos dizer com isso que é muito difícil a separação entre desigualdade e diferença numa sociedade tão classificatória como é a sociedade capitalista e eurocêntrica.

Assim, como apoio expositivo destas reflexões, buscamos a ideia de totalidade aberta (nunca alcançada/ finalizada), desdobrada em outras totalidades, também abertas, todas marcadas por desigualdades e/ou diferenças. Pensamos ser possível falar de totalidades desiguais e desigualizadoras e de totalidades de diferenças. Ambas as totalidades se interconectam já que o fato de existirem desigualdades não exclui clivagens assentadas em diferenças. Os sujeitos sociais produtores do espaço são incorporados ou incorporamse a esse complexo jogo de interações.

O conceito de escala atravessa essas interações e torna-se um forte evidenciador das desigualdades ao se observarem as distintas maneiras de vivenciar as escalas. Por exemplo, a capacidade de um usineiro de açúcar com casa-sede na fazenda, onde disfruta de todo 
conforto, com outra residência de frente para o mar em Ipanema, e ainda outra em Paris, contrasta com a de um cortador de cana que vive no bairro periférico da cidade do interior e se desloca de caminhão diariamente para o canavial e daí para casa. Ambos estão inseridos num mesmo sistema produtivo, mas a possibilidade do usineiro viver a multiescalaridade (estar conectado e, efetivamente, viver múltiplas situações escalares simultaneamente) e a transescalaridade (atravessar, com seus investimentos, diversas escalas) é muito superior àquelas do cortador de cana quase restrito à monoescalaridade. Com isso, retoma-se a importância da abordagem topológica da multi/transescalaridade.

Aí se vê que, enquanto os detentores do capital hegemônico exercitam (em áreas urbanas e rurais) a sua multiescalaridade na ação concentradora dos meios de produção, os que a eles se opõem têm dificuldade de atuar multiescalarmente, já que raramente se percebe (e não é difundido), por exemplo, que a luta por terra para moradia ou para produzir deve ser unificada nas escalas em que se realiza, em áreas rurais ou áreas urbanas. As ações têm sido pulverizadas e são raros os indícios de integração entre movimentos sociais urbanos e rurais. Aqui é necessário lembrar que os recortes políticoadministrativos (bairro, município, estado) podem atuar como verdadeiras armadilhas escalares ao isolarem fenômenos que ultrapassam seus limites. A ação de fenômenos situada fora dos limites de uma unidade político-administrativa pode ser determinante para efeitos detectados no interior dessas unidades. Ao recortarmos o espaço podemos perder a verdadeira escala de atuação dos fenômenos.

Se essa situação se complexificar com relações de gênero e de raça, ficam explicitadas as dificuldades aludidas acima: distinguir desigualdade e diferença. As urbanidades são portadoras dessas desigualdades e dessas diferenças vividas nas cidades e difundidas como "modo de vida" para todo o planeta, evidenciando graus e naturezas contrastantes.

A base referencial (geral) da abordagem que aqui se apresenta provém, inicialmente, de Marx, quando, sempre preocupado com a propriedade da terra, enfatiza a divisão de trabalho e a oposição entre cidade e campo. Em Marx (2011, p. 59-60) pode-se ver novamente a distinção entre proprietários e não proprietários da terra e citadinos e rurais, apontando as contraposições nas maneiras de pensar e visões da vida entre os moradores do campo e da cidade. Mesmo evidenciando uma visão evolucionista, urbanocêntrica e dicotômica, acende uma luz sobre os modos de pensar e agir distintos. Foi a partir desse ponto que se iniciou em nossos trabalhos a ideia de que tais visões da vida, necessariamente, iriam progressivamente sendo mescladas na medida em que mais se intensificavam as relações entre campo e cidade, unificando, cada vez mais, esses dois subespaços.

Entretanto, a aludida base referencial fortaleceuse com Henri Lefebvre $(1978,1999)$, ao retomar essas formulações marxianas, apresentando a cidade como obra (construção física, arquitetônica) e o urbano como uma racionalidade (modo de produzir, viver, pensar e agir) que se universaliza em dimensão planetária. Esta última ideia permeia todas as reflexões efetuadas neste trabalho, já que pode ser relacionada ao espaço - uma nova racionalidade espacial conduzida pela lógica do capitalismo - em sua multidimensionalidade e no seu movimento de totalização (totalidade nunca alcançada) ${ }^{7}$.

Além da base referencial acima apontada, os conceitos básicos que fundamentam nossa exposição são: espaço, com base em Harvey (2012), Lefebvre (2008) e Santos (1994 e 1996); território, à maneira de Haesbaert (2004, 2014); lugar, como elaborado por Massey (2008); e metropolização do espaço conforme Kayser (1973; 1990) e Lencioni $(2013 ; 2015)$. As formulações desses autores amparam a consideração de relações urbanorurais como evidências de um espaço relativo/relacional (contendo, mas ultrapassando, o espaço absoluto, limitado, cartesiano), do espaço como condição para a reprodução social da vida que ocorre nos lugares de modo multi/transescalar por estarem integrados a sistemas de objetos e de ações (e de representações) levadas a cabo por aqueles que atuam produzindo esse espaço nas distintas e simultâneas escalas que tais ações admitem. Multiterritorialidades criadas em áreas rurais explicitam as relações de poder assimétricas (hierarquizadoras) entre (e dentro) (d)as diferentes localidades rurais e entre os lugares rurais e os urbanos. As desigualdades/fragmentações estão em todas as parcelas/fragmentos espaciais.

A partir dessas leituras é que passamos a formular noções a respeito do espaço como totalidade e de urbanização no rural. Definia-se, assim, a urbanização (o urbano planetário) como processo predominantemente ligado à industrialização, o qual marcou o século $X X$ para os países denominados centrais e atualmente abrangendo praticamente toda superfície terrestre como racionalidade, portanto, não se tratando de espaço construído. Queremos dizer com isso que ao falar de urbanização do espaço referimo-nos a um

7 É preciso tomar cuidado com interpretações homogeneizadoras das formulações desses autores. O particular, o singular, o subjetivo não desaparecem no processo de "urbanização planetária" apontado acima. Este último autor apontanos para a tríade homogeneização-fragmentação-hierarquização para evidenciar as intensas contradições existentes entre a pretendida homogeneização (nunca alcançada) e as resistências a ela observadas; ao mesmo tempo explicita-se a hierarquização, fruto das distintas valorizações/precificações/investimentos desigualizadores dos espaços urbanos e rurais. 
processo comportamental, ideológico e, sobretudo, à difusão do ritmo da indústria para todas as dimensões da vida da maior parte das pessoas. Sabemos o quão desigualmente esses comportamentos e esse ritmo de consumir, produzir e viver se manifestam no cotidiano. Percebem-se intensidades muito distintas nesse processo de difusão planetária, no qual a referida racionalidade urbana vai se apresentar como portadora dos símbolos e signos do capitalismo expandido a partir da Europa ocidental.

Se já escrevemos sobre cidade e campo (como formas aparentes do espaço), sobre urbano e rural (como processos) e sobre urbanização no rural (e não do rural, conforme Rua [2002]), apontamos, aqui, a metropolização do espaço, processo mais complexo, marcando o presente momento da urbanização, o qual representa a lógica financeira que afeta, sobremaneira, espaços tão integrados às metrópoles - seguindo as formulações de Lencioni (2013; 2015), as quais têm dado suporte à discussão que temos elaborado acerca das interações da metropolização do espaço com as relações urbano-rurais.

A metropolização do espaço refere-se a um conjunto de transformações cuja dinâmica ultrapassa os limites da metrópole e da região metropolitana. Elas evidenciam o derramamento dos atributos da metrópole por uma vasta região em metropolização, nas quais se percebem alterações espaciais de ordem econômica, política e social/cultural na vida cotidiana dos moradores de grandes, médias e pequenas cidades ou áreas rurais. Tais alterações, ao se manifestarem no espaço, muito raramente se evidenciam à maneira de uma "mancha de óleo" contínua a partir da metrópole. Poucas vezes se percebe continuidade ou contiguidade nos "desenhos" de um espaço de metropolização bem como nas urbanidades no rural.

Ao se falar em metropolização do espaço, enfatizase a dimensão financeira evidente na mercadificação (lógica do mercado) e precificação (tudo terá um preço atribuído). Em fins do século XX e no século XXI, superpõese o processo de metropolização ao de urbanização, sem excluí-lo e dando-lhe continuidade. Sobre isso, em Rua (2019, p. 300), escreveu-se que:

O momento atual é marcado por uma lógica financeira que ultrapassa o momento da urbanização (relacionado com a industrialização) e nos apresenta a metropolização (mais ligada à desindustrialização e desconcentração industrial, à financeirização das relações sociais e a uma maior concentração da gestão). Sumariamente, pode - se interpretar a urbanização como um processo que alcança, mesmo que desigualmente, todo o espaço integrado à difusão da lógica capitalista. A metropolização constitui-se num novo momento da espacialidade, continuando e integrando a urbanização. Embora os dois momentos se distingam em diversos aspectos (abrangência territorial, intensidade e importância dos fluxos imateriais, o significado da concentração da gestão e da desconcentração da produção, o papel do consumo etc.), constituem apenas isso: momentos da permanente (re)espacialização do capitalismo na busca de novas maneiras de exercer a acumulação.

O espaço torna-se, assim, mais complexo (urbano+rural, integrados ao fenômeno da metropolização), o que propõe novos desafios analíticos, nos quais à racionalidade e ao ritmo industriais acrescenta-se a lógica da financeirização, permitindonos, com isso, falar de urbano-metropolitano.

Assim como as urbanidades no rural, também a metropolização vai se apresentar de maneira descontínua e será notada em localizações desigualizadoras, já que estas tornam-se preferenciais para os investimentos de natureza diversa, manifestados materialmente ou imaterialmente nas alterações de hábitos, costumes e maneiras de viver dos moradores das localidades integradas por esses dois fenômenos geográficos - a metropolização e as urbanidades no rural, de natureza distinta. Podemos falar de "urbano-metropolitanidades" no rural, significando a coexistência dos dois processos (urbano e metropolitano) integrados, mas atualmente mais explicitados pelo segundo. Seriam, então, como já vimos, momentos da permanente (re)espacialização do capitalismo. Como exemplos da integração desses dois momentos, podemos lembrar a importância do rádio, da televisão, da maquinificação e da quimificação como elementos difusores dos modos de vida urbanos e da lógica industrial atravessando todas as dimensões da vida cotidiana em áreas rurais, mesmo com distintas intensidades.

Sem deixarem de permanecer como relevantes os elementos ligados à urbanização do espaço acima exemplificados, podemos pensar no celular, na internet, nas redes a cabo, na produção para nichos específicos de mercado (orgânicos, por exemplo), na moda e na importância do marketing, todos integrados à lógica da financeirização, espelho maior da metropolização do espaço.

Pode parecer estranho colocar-se o rádio, o celular e serviços a partir da internet (como o Internet Banking $\mathrm{e}$ as redes sociais) lado a lado como elementos difusores da racionalidade urbano-metropolitana. Mas é preciso recordar as diferenças do espaço planetário e as desigualdades na vivência das múltiplas escalas. Como mensurar a importância do rádio na alteração dos modos de vida de uma família camponesa que disponha 
apenas desse meio de comunicação? Muito próximo desse rádio, podem situar-se outras maneiras de integrar as escalas da vida. Podem estar próximos em termos de escala topográfica, mas estarão distantes em termos de escala topológica. Serão sujeitos desigualmente e diferentemente voltados para o mundo. 0 gênero, a raça, a etnia, a propriedade fundiária e a classe social estarão presentes como alguns dos elementos estruturantes das particularidades e das singularidades que marcam a infinita multiplicidade de trajetórias nos lugares rurais.

Todos os elementos do urbano permanecerão no metropolitano, como já dito anteriormente - a ideia de urbano-metropolitanidades procura integrar todos esses elementos na multiescalaridade que marca as espacialidades do momento atual do capitalismo global.

Assim, a metropolização do espaço apresentase como um processo múltiplo e complexo, que gera profundas modificações nos arranjos espaciais e nas relações sociais nas áreas por ela integradas. As urbanidades no rural evidenciam essas modificações. Em ambas é possível observar uma crescente fragmentação do espaço, "pedras do mosaico" (sem delimitação definida ou fixa), de particularismos e singularidades em relações multiescalares e hierarquizadas.

As reflexões até aqui efetuadas servem como possíveis bases para distintas aproximações com a empiria, isto é, aproximações subjetivas com um real também subjetivo, já que de difícil apropriação, porque inatingível. Tal dificuldade de aproximação com o real exige mediações que podem ser oriundas de distintas matrizes teórico-conceituais. A ciência geográfica vem desenvolvendo diversas possibilidades de análise dos fenômenos que constituem esse real complexo, em nossa abordagem, construído a partir da noção de urbanidades no rural. A totalidade-espaço será percebida na junção do urbano+rural integrados por tal noção. Disso trataremos na seção a seguir.

Urbanidades no rural: procurando uma aproximação com a multiplicidade do real

Integrar teoria e empiria quase sempre se torna um exercício dificultado pelas diversas possibilidades de aproximação com a realidade. Empiria e realidade constituem-se sinônimos? Parece-nos que não. Ao escrever sobre empiria quase sempre nos referimos a uma experiência cotidiana sensível pouco elaborada racionalmente. Poderíamos relacioná-la, também, com a aparência, com as primeiras impressões e com uma exemplificação à qual possa vir a ser relacionada com um processo mais amplo.

A aproximação com a realidade já vai nos exigir uma tensão entre a subjetividade da aproximação e a realidade em si mesma. Por exemplo, para Kosik (1976, p. 43) a realidade é incognoscível, uma vez que sempre é possível adicionar-lhe novos elementos, fatos esquecidos ou ainda não descobertos, mediante um infinito acrescentamento, que se apresenta como um momento do todo. Para essa aproximação, propõe a tridimensionalidade como princípio metodológico. Também Lefebvre (1980) nos recorda que a presença (o real) nunca se alcança por estar obscurecido por representações que o compõem. Parece ser possível estabelecer uma relação entre o conceito de representações lefebvriano e a pseudoconcreticidade (realidade nunca alcançada) desenvolvida por Kosik. Lefebvre aponta que a tridimensionalidade implica em um infinito virtual. Procurando apoio em Lencioni (2018), observa-se que o pensamento triádico de Lefebvre conduz a um modelo de pensamento com maior flexibilidade que uma visão binária ou unitária, correspondendo a ritmos e a processos. Segundo a autora, o pensamento lefebvriano jamais deixará de nos apontar para o devir, para o possível e para a permanente possibilidade de um novo começo.

Uma autora que muito enriquece essa busca (de um sentido subjetivo de aproximação com o real é Doreen Massey. Essa geógrafa apresenta múltiplas influências na formulação de seu pensamento: influências da dialética materialista, do pós-estruturalismo e da abordagem centrada na complexidade podem ser identificados em Massey (2008), por exemplo. Aí escreve que o espaço deve ser encarado como aberto, múltiplo e relacional, sempre em devir, capaz de possibilitar novas "relaçõesumas-com-as-outras" de trajetórias diversas.

Nessa busca de aproximação com o real e a multiplicidade que ele contém, procuramos correspondências entre esses autores mesmo reconhecendo suas abordagens distintas, mas, em nosso ponto de vista, não incompatíveis. As ideias de totalidade concreta, momentos do real, representações, o devir como virtualidade, as múltiplas trajetórias num espaço sempre em movimento vão reforçar as reflexões anteriormente efetuadas sobre totalidadeespaço, representada pelo urbano planetário numa universalização de sua racionalidade.

Assim, ao pensar sobre as relações urbano-rurais tentamos percebê-las como estando condicionadas por essa planetarização e por essa racionalidade urbanometropolitana. Entretanto, sempre apoiado nas análises dos autores supracitados, isso nunca significará qualquer tipo de homogeneidade. A multiplicidade expressa nos rurais evidencia as múltiplas trajetórias e os momentos do real que marcarão cada parte do todo espacial e das infinitas interações nele realizáveis. 
Pensamos que a ideia de urbanidades no rural possibilita, a um sótempo, contemplar, multiescalarmente, o todo, as partes, a multiplicidade, a desigualdade e a diferença conforme apontado em outra parte deste texto.

A abordagem citada vem sendo desenvolvida desde o final dos anos 90, na virada para 2000. A partir da leitura dos trabalhos de Poulle e Gorgeu (1997) e de Kayser $(1973,1990,1996)$ sobre as relações campocidade, via-se como o espaço rural francês estava sendo revolucionado por outras relações urbano-rurais. Essas leituras provocaram as inquietações intelectuais que já há muito nos desafiavam ao observar o rural brasileiro. Interessados em compreender os movimentos sociais no campo e as motivações que lhes davam sustentação, procurava-se maneiras de explicar como os trabalhadores rurais sem-terra, mas vivendo em bairros periféricos das cidades, se identificavam. Seriam eles urbanos ou rurais? Estatisticamente seriam considerados como urbanos, enquanto, por sua ocupação, considerados como mãode-obra rural. Desde logo se percebeu que não se trataria apenas de uma questão estatística ou de localização de residência. Ao se referir à identidade desses trabalhadores, já se buscava o conteúdo político nela contido. Greves nos canaviais de São Paulo em meados dos anos 80 , organizadas pelos trabalhadores rurais nas cidades, já apontavam a necessidade política de não somente integrar os movimentos dos trabalhadores rurais aos dos trabalhadores urbanos, como procurar formulações teórico-conceituais que as pudessem explicar. Concordando com Massey (2004), podemos considerar o espaço como esfera da possibilidade da existência da multiplicidade, na qual se deve priorizar a existência de mais de uma voz. Tal voz não se revelará como única, mesmo que se proponha a união entre os movimentos reivindicatórios. A união desejada não deve excluir a multiplicidade de trajetórias no lugar.

Ao buscar tais conceituações deparamo-nos com problemas enraizados nas Ciências Sociais e na Geografia, em particular, que demonstravam a impossibilidade de continuar a utilizar essencialismos reducionistas, os quais, como se observa, já há muito não refletiam a realidade. Afinal de contas, o urbano e o rural ainda representavam as dicotomias ou os antagonismos que os caracterizavam há séculos? 0 conceito fechado, estatisticamente balizado, de urbano, contemplava a complexidade que se observava nos movimentos dos trabalhadores rurais sem-terra, na formação dos grandes complexos agroindustriais (atualmente, genericamente referidos como agronegócio) ou nas políticas oficiais voltadas para a agricultura e para o desenvolvimento agrícola? Nessas condições, como separar o setor primário do setor secundário e do terciário?

A Geografia deveria procurar maneiras de explicar a integração espacial que se processava ao longo de décadas e que não poderia ser representada pelo antagonismo urbano x rural, por exemplo. A necessidade de um conceito integrador que abarcasse, a um só tempo, a homogeneização que se percebia pelas novas formas de produzir, de circular e de distribuir as mercadorias levou os geógrafos à consideração do espaço como totalidade, como já visto. Nesse espaço-totalidade teriam de estar contidas todas as fragmentações que pudessem ser integradas - urbano, rural, industrial, fluminense, baiano, amazônico, sulista ou quaisquer outras denominações que as partes desse espaço expressem, em infinitas singularidades. Assim, o espaço se complexifica e desafia novas compreensões.

Desse modo, a ideia das urbanidades no rural busca restaurar essa dinâmica espacial integradora/ totalizadora, em constante transformação. Considera-se que as urbanidades se manifestam de diversas maneiras, seja através de elementos materiais (que se evidenciam sobretudo na transformação nos aspectos relacionados à comunicação, ao transporte, às técnicas de produção, às novas estruturas de origem urbana presentes nos espaços rurais), seja através de elementos imateriais uma racionalidade divulgada a partir do urbano, como Lefebvre (1978) nos aponta.

Atualizando a discussão sobre indicadores de urbanidades no rural, apresentados em trabalhos anteriores, aquireformula-seessa proposição, procurando relacioná-la com a ideia de partes/totalidade-espaço, já referida anteriormente. 0 que se busca é demonstrar que é possível fragmentar, para fins analíticos, essa totalidade. Partes, dimensões, elementos, indicadores (denominações variadas de acordo com os objetivos do pesquisador) estarão relacionados a ações e às intencionalidades dos sujeitos sociais em seus projetos conflituosos na produção de espacialidades. De acordo com Lencioni (2018, p. 254) "o importante é compreender que as relações que se estabelecem entre os elementos, sejam eles objetos, fatos, fenômenos ou processos não se estabelecem de forma absoluta". A autora completa: "pois [estes] não são independentes e soberanos, como se constituíssem cada um deles, uma causa absoluta de um ou vários acontecimentos" (idem).

Ressalta-se, de antemão, que é preciso tomar alguns cuidados ao selecionar e elencar tais dimensões e seus elementos constitutivos. Estes não devem ser confundidos com variáveis em uma matriz de possíveis cruzamentos, com caráter objetivo. Tal procedimento anularia a dialética espacial seguindo a perspectiva de Massey (2005), na qual as conexões são sempre mutáveis 
e conjunturais. Como já apresentado anteriormente, se trabalhamos com espaço de interações, sempre aberto a novas possibilidades, não poderíamos fechá-lo em uma matriz de variáveis pré-determinadas, nas quais as subjetividades estarão diluídas em generalizações que escondem os conflitos e o papel político dos sujeitos que se espacializam de maneiras diversas, contraditórias e integradas a distintas escalas de atuação. Tais subjetividades atravessam a escolha dos elementos constitutivos de cada dimensão e devem ter prioridade na análise desses elementos. Quer dizer, para nós, tornase mais importante quem produz as ações expressadas nos indicadores/elementos e a quais processos elas estão integradas do que simplesmente elencá-las num rol com características (pseudo)objetivas.

Outro aspecto que deve nortear a escolha dos indicadores/elementos é a localização do objeto de estudo enquanto empirização dos processos analisados. Se, em nossa prática, elencamos estas dimensões e estes elementos a partir das experiências em trabalhos de pesquisa na região serrana fluminense, que dimensões e elementos seriam fundamentais numa região dominada pelo agronegócio, por grandes projetos de exploração mineral ou em áreas ocupadas por populações ribeirinhas? Sempre devem ser levadas em consideração as bases constitutivas (e a historicidade acumulada, tanto no campo funcional quanto no simbólico) da regionalização como suporte das relações urbano-rurais. Em um país tão amplo como é o Brasil, torna-se estranho pensar dimensões/elementos constitutivos do espaço uniformizadores de realidade tão variada.

Tais colocações nos apontam para outros cuidados que devemos tomar ao observar a proposta que nos movimenta numa perspectiva didática de compreensão da multidimensionalidade do espaço. Tais dimensões não se reduzem às quatro apontadas abaixo (físiconatural; simbólico-cultural; socioeconômica e técnica), já que são conjunturais. Também os indicadores/ elementos que aqui são elencados como componentes das dimensões terão de ser aceitos como provisórios (cambiantes e conjunturais). Esse método põe em xeque as certezas que a consideração do espaço como fechado, delimitado, com elementos pré-estabelecidos nos garantiria.

Assim, é com muita cautela que se propõe a sequência a seguir, mesmo com risco de se apresentar reducionista e como antítese do método analítico apontado anteriormente. A intenção é que se constituam múltiplas interações entre as dimensões dos elementos apontados, triadicamente constituídos, utilizados especificamente em cada dimensão (ou entrecruzandoas), mas sem perder a perspectiva do espaço como totalidade. Como exemplo, podemos pensar no indicador/ elemento "turismo rural", quando analisado a partir da segunda dimensão do espaço (simbólico-cultural). Ao se trabalhar com esse elemento, necessariamente, deve-se buscar interações com as outras dimensões e com outros elementos (a paisagem e a natureza, a constituição da renda familiar, o conjunto de técnicas de comunicação, dentre muitos outros elementos, de outras dimensões). Vê-se, assim, as infinitas possibilidades de interações que o espaço nos oferece ao considerá-lo multidimensional, multiescalar e uma totalidade aberta. Daremos, aqui, alguns exemplos dessas dimensões traduzidos em tais elementos:

1) de ordem físico-natural: o sítio no qual a localidade está construída ou onde as atividades rurais são realizadas (aspectos geomorfológicos e climáticos, carreamento de solos, deslizamentos, enchentes, etc.). Os aspectos físico-naturais influenciam a consolidação das direções do povoamento e a construção de rodovias até as direções em que a maior valorização (precificação) do solo ocorrem. Observa-se, nessa dimensão, as necessárias interações naturais e sociais, que sempre devem ser focalizadas. Nesse ponto, pode ser lembrada a importância de considerar o ambiente como noção integradora, não limitado à "natureza primeira", nem reduzindo a ação dos homens em sociedade a um abstrato "fator antrópico", como nos relembra Souza (2019, p.14). Não devemos esquecer a influência dos chamados elementos naturais nas próprias configurações espaciais. Ao escrever sobre direcionamento de estradas e de linhas de povoamento fortemente condicionadas pela topografia e pela rede hidrográfica, também se estará apresentando as principais linhas de urbanidades no rural, adensadas nessas localizações;

2) de ordem simbólico-cultural: a memória coletiva e valorização da tradição, a existência (ou não) de um localismo "conservador", a convivência com o turismo rural e o veraneio, a autoestima, a relação com a natureza em seus aspectos imateriais e as percepções ecológico-ambientais e relações mais efetivas com os territórios da vida (populações indígenas, quilombolas, camponeses, etc.). Aqui podem ser destacados alguns aspectos simbólicos que, por séculos, vêm marcando as pessoas residentes em áreas consideradas rurais. Atualmente alguns desses símbolos são recriados em áreas urbanas constituindo-se em um certo tipo de ruralidade nas cidades. Nesse conjunto de elementos evidenciam-se as contradições entre o que vem de fora (moderno) e os valores locais (atualmente revalorizados, às vezes somente como mercadoria). Procura-se destacar o conceito de território em suas dimensões tanto funcional como simbólica, integradas numa multiterritorialidade (experiência de vários territórios simultaneamente, cf. Haesbaert, 2004) e numa aproximação com o conceito de lugar para Massey - feixe ou imbricação de múltiplas trajetórias, sempre aberto a novas conexões;

3) de ordem socioeconômica: a dominação capitalista do espaço, conflitos entre o valor de uso e o valor de troca, a renda territorial e o preço da terra, 
a importância da propriedade da terra (privada, pública ou comunitária), a renda gerada pelo turismo, a criação de novos empregos, a presença de indústrias (ligadas ou não à produção agrícola), assistencialismo oficial e de ONGs, o consumo e o consumismo, associativismo, participação política e movimentos reivindicatórios. Nesse conjunto destacam-se três aspectos: a composição da renda familiar (de origem agrícola e não-agrícola), a precificação da terra em moldes cada vez mais semelhantes aos urbanos e a racionalidade do modo de produção capitalista atravessando todas as dimensões da vida cotidiana. Um conceito geográfico que pode ser explorado ao se trabalhar com este conjunto de indicadores é o conceito de escala. Falou-se, anteriormente, de escala geral do capitalismo e de leituras particulares pelos sujeitos locais, os quais adaptavam e integravam o valor de troca (mercadificação e precificação) como lei geral do capitalismo às necessidades cotidianas do lugar. Devem ser destacados alguns aspectos, como, por exemplo, aquele que diz respeito à multiplicidade de sujeitos produtores do espaço ao atuarem multiescalarmente - quanto mais poderoso econômica, política e socialmente se apresentar o sujeito em sua ação, tanto mais explícita se tornará a desigualdade frente àqueles sujeitos com menor capacidade de exercício dessa multiescalaridade, o que não invalida a força e a importância dos movimentos de resistência e de contestação a essa hegemonia, abrindo perspectivas de produção de outras espacialidades e territorialidades;

4) de ordem técnica: adoção de novas tecnologias, inclusive de informação, presença de produtos agrícolas diferenciados, formas de comercialização que integram o lugar a redes mais amplas de raiz metropolitana e internacional, saneamento básico e coleta de lixo, existência de supermercados, estudos sobre a poluição da água e do lençol freático, cuidados no uso de agrotóxicos. Neste conjunto deve ser enfatizada a racionalidade técnico-científica, a qual influencia não somente os meios de produção, de circulação e comunicação, mas também a própria percepção das relações sociedade-natureza, agora revestidas de uma cientificidade portada pelos técnicos, promovendo, nessa interação, aspectos positivos e negativos, de difícil equacionamento. Nesse ponto, pode-se retornar às formulações do geógrafo Milton Santos em sua relação técnica-espaço, quando escreve que "as técnicas, funciona[m] como sistemas que marcam as diversas épocas, [...] examinadas através de sua própria história e vistas não apenas no seu aspecto material, mas também nos seus aspectos imateriais. [...] Objetos naturais e objetos fabricados pelo homem podem ser analisados conforme o seu respectivo conteúdo, ou, em outras palavras, conforme sua condição técnica, e o mesmo pode ser dito das ações, que se distinguem segundo os diversos graus de intencionalidade e racionalidade" (SANTOS, 1996, p. 14). Assim, percebe-se a potência do espaço como conjunto indissociável de objetos (naturais e artificiais) e ações, o que, mais uma vez, evidencia a sua multidimensionalidade tão enfatizada em nosso trabalho preocupado com a melhor compreensão das relações urbano-rurais sob a lógica capitalista.

Esse conjunto de elementos procura orientar pesquisas que permitam um melhor reconhecimento das relações urbano-rurais destacando a crescente complexidade do campo brasileiro. Na verdade, não se constituem em quatro segmentos, como pode parecer. Admitem-se, como já vimos, múltiplas interações e imbricações entre os elementos e as dimensões, constituindo novas formulações, sempre possíveis. Os conceitos de natureza, território, lugar, escala e técnica foram utilizados apenas como exemplos relacionados a cada dimensão. Entretanto é preciso ressaltar que eles estarão presentes em todas as dimensões acima elencadas. Outros poderiam ser, também, mencionados. Da mesma maneira outras dimensões poderiam ser adicionadas, como, por exemplo a política. Embora não tenha sido destacada, essa dimensão atravessa todas as outras, bem como todos os elementos que as compõem e está presente em cada momento deste trabalho como comprometimento maior. Mais uma vez ressalta-se a possibilidade de infinitos entrecruzamentos tanto das dimensões quanto dos elementos que, subjetivamente, em cada uma foram alocados.

Diversos trabalhos já têm sido apresentados seguindo essa perspectiva teórico-conceitual e metodológica, mesmo que com distintos procedimentos de investigação. Dentre esses citamos Oliveira (2007), Marafon (2014), Candiotto e Corrêa (2008), Duarte Ramos (2014), Rua (2013, 2015), Agueda (2019) e Simoni (2019). Esses trabalhos ora enfocando a renda da terra, os megaprojetos, ou o turismo rural e as novas formas de comunicação, consideram as urbanidades no rural como abordagem relevante para uma melhor compreensão da espacialidade contemporânea, ao procurar integrar as escalas da globalização com as da vida cotidiana dos moradores de um lugar, atravessando distintas dimensões do espaço.

Como demonstrado nos exemplos apresentados, é preciso resgatar a multiescalaridade da ação (intencional) dos sujeitos hegemônicos e hegemonizados. 0 capital financeiro (integrando capitais de várias origens) vem aceleradamente integrando o rural e o urbano através de investimentos em infraestruturas, serviços em áreas rurais, empreendimentos imobiliários, turismo e veraneio, além da compra de terras, da mesma forma que nas cidades esses investimentos atuam como desigualizadores do espaço geográfico. Qual é a dinâmica desses investimentos desigualizadores? Como aceleram o movimento do (e no) espaço, evidenciando desenvolvimentos geográficos desiguais? Que alterações ocorrem, e são percebidas e vividas no lugar fruto dessas interações, concebidas nesse espaço em metropolização? Como um lugar rural vai interagir com os processos tramados em escalas supralocais?

Esse processo de integração espacial entre o rural e 
o urbano se expressa de maneira desigual mas é parte da mesma lógica homogeneizadora (na escala geral do capitalismo urbano-metropolitano), fragmentadora (diferenciação, desdiferenciação, desigualização) e hierarquizadora (mercadificação, precificação, valorização), componentes combinados no espaço e que se evidenciam sob a forma de urbanidades no rural - agora, porém, inseridos em um processo de metropolização do espaço.

Ao se enfatizar a totalidade do espaço, fugimos às dicotomias que, por vezes, se manifestam até mesmo nos discursos sobre a manutenção das particularidades e singularidades do rural (algo que é sempre necessário ressaltar), englobadas no rótulo de ruralidades ou novas ruralidades. Pensamos que tais discursos podem mascarar os jogos de poder tão assimétricos entre um urbano "genérico", falsamente homogêneo, e um rural "genérico", também falsamente homogêneo. Essa assimetria pode ser percebida até mesmo na linguística e nos nomes que as evidenciam, como por exemplo:

A polarização construída na modernidade e exercida pela cidade concentrou nela poder político, capital, cultura, moda, etc e projetou um modo de viver, pensar e agir urbano que, cada vez mais, tem subordinado o campo - visto como atrasado, incivilizado, rústico. Estas imagens são reforçadas pela linguagem: civis-civil-civilizado; urbs-urbano-urbanidade; polis-polido-educado-político; burg-burguês. O próprio termo cidade (em suas múltiplas origens) é apropriado para criar a representação social do "burguês polido, político, educado, cidadão". O rural - rus, ruris, em latim, que derivou em rude - passa a ser visto como o "outro", nessas representações (RUA, 2005).

Ao utilizarmos a expressão "urbanidades no rural" queremos demonstrar essa assimetria de poder e, ao mesmo tempo, evidenciar a permanência do rural em espaços urbanizados, no sentido lefebvriano de "urbano" e, mais recentemente, de urbano-metropolitano, dando continuidade ao mesmo processo. Embora num primeiro momento marcado pela concentração espacial e pela industrialização, atualmente nele se enfatiza a importância da desconcentração espacial das atividades econômicas e concentração da gestão. Essa desconcentração centralizada mobiliza sujeitos produtores do espaço, num jogo complexo, que o torna um campo de forças onde as regras definidas para e pelo capital se expressam em novas geografias e em múltiplas escalas.

Toda a discussão acima efetuada serve para destacar que, em nossa reflexão, o urbano deve ser entendido à maneira de Lefebvre, como já apontado. Para nós não se tratam de números ou índices, procura-se compreender o processo de espraiamento da racionalidade urbana como modo de ativar comportamentos, atitudes e hábitos cada vez mais influenciados social, cultural e economicamente, pela maneira de viver até algum tempo exclusivo das cidades e nas metrópoles.

\section{Considerações Finais}

Neste ponto decidimos retomar Rua (2019), com algumas alterações, procurando dar destaque às preocupações que orientam nossas pesquisas e reflexões. Buscamos evidenciar as relações urbanorurais integradas ao recente processo de metropolização que vem se tornando uma das marcas da espacialidade contemporânea. Para alcançá-lo, optamos por discutir as urbanidades no rural, considerando-as em uma abordagem que recompõe a totalidade do espaço (urbano + rural), fato que não tem sido priorizado por diversos autores. Tal abordagem contribui, também, no destaque à multiescalaridade e transescalaridade dos processos espaciais, necessária para a consideração da totalidadeespaço, integrando os moradores das localidades rurais, das cidades médias e das metrópoles a racionalidades hegemônicas da modernidade, compondo, com isso, novas imagens e representações do urbano e do rural. Tais processos espaciais vêm sendo percebidos em situações geográficas concretas bastante variadas e pesquisadas por nós há tempos.

Muitas localidades rurais contêm cada vez mais atributos até recentemente exclusivos de áreas urbanas - ou assim considerados. Que rural é esse? É novo? Em relação a que? Não existia antes ou é uma questão de intensidade das transformações? Essas perguntas continuarão colocadas. Ainda procuramos compreendêlo, pois novas indagações e problemáticas estão presentes nele a cada dia, participantes da dinâmica geral das metamorfoses do espaço.

Nossa perspectiva analítica pode ser resumida desta maneira: o espaço geográfico constitui uma totalidade em movimento, isto é, em processo, em permanente mudança; essa totalidade em movimento altera-se consoante as transformações da sociedade (produtora e produto do espaço com o qual interage), porém considerando-as historicamente construídas; essa construção apresenta-se como espaço-temporal e participa da evolução das relações de produção e de trabalho, características de cada momento.

Pensamos ter explicitado as três perspectivas apresentados no início deste artigo: o espaço como totalidade, a multiescalaridade da ação dos sujeitos envolvidos na produção do espaço e a importância de estabelecer uma análise crítica das assimetrias de poder entre os distintos sujeitos atuantes nesse movimento 
de produção do espaço e a relevância de se destacar a metropolização como momento atual do processo geral de urbanização.

Superada a visão dicotômica das relações urbanorurais, deve-se ressaltar a ideia de que este espaço em totalização é um espaço de sujeitos: sociais, políticos, econômicos, culturais, que estão sempre em disputa - o que nos leva à ideia de leituras desigualizadoras e diferenciadoras de tal movimento, do capitalismo em expansão nas suas diversas modalidades e escalas. Como esse capitalismo é lido, percebido, pelas localidades, pelos sujeitos (urbano, rurais, hibridizados)? Quais propostas de superação dessa forma de organização societária podem advir das escalas locais de ação?

Logo, como se viu neste trabalho, deve-se destacar a importância da multi/transescalaridade dos processos no espaço - entre a escala mais geral do capital e a do Estado, e a escala mais local. Esse movimento é sempre desigual e desigualizador. 0 jogo multi/transescalar, assim como a perspectiva do espaço como totalidade, está interconectado ao processo de metropolização do espaço. 0 espaço rural, em sua multidimensionalidade, encontra-se integrado à lógica da globalização do capital e à lógica da metropolização - sobretudo neste momento de financeirização das relações sociais de produção. 


\section{Referências}

AGNEW, J. (2011) Space and Place. In: AGNEW, J. e LIVINGSTONE, D. (eds.) Handbook of Geographical Knowledge. London: Sage, p. 316-330.

AGUEDA, B. (2019) Relações urbano-rurais e desenvolvimentos geográficos desiguais: transformações espaciais nas localidades de Vargem Grande (Teresópolis - RJ) E Barracão Dos Mendes (Nova Friburgo - RJ) Dissertação (mestrado)Pontifícia Universidade Católica do Rio de Janeiro, Departamento de Geografia e Meio Ambiente.

ALENCAR, C. M. M. e MOREIRA, R. (2005) Campo e cidade metropolitanos: uma noção inteira para pensar o desenvolvimento humano contemporâneo. In: MOREIRA, R. (org.). Identidades sociais: ruralidades no Brasil contemporâneo. Rio de Janeiro, DP\&A, p. 295-316.

CANDIOTTO, L. Z. P.; CORRÊA, W. K. (2008) Ruralidades, urbanidades e a tecnicização do rural no contexto do debate cidade-campo. CAMPO-TERRITÓRIO: Revista de Geografia Agrária, Uberlândia, v.3, n.5, p.214-242.

DUARTE RAMOS, H. (2014) Urbanidades no rural: as transformações na Comunidade Macaúba - Catalão (GO) / Hugo Roberto Duarte Ramos. Dissertação (Mestrado) - Universidade Federal de Goiás, Regional Catalão, Programa de Pós-Graduação em Geografia, Catalão.

HAESBAERT, R. (1999) Região, Diversidade Territorial e Globalização. GEOgraphia v.1, n.1. p 15-39.

(2004) O mito da desterritorialização: do "fim dos territórios" à multiterritorialidade. Rio de Janeiro: Bertrand

Brasil.

(2014) Viver no limite: território e multi/transterritorialidade em tempos de in-segurança e contenção. 1 ed. Rio de Janeiro, Bertrand Brasil, 320p.

HARVEY, D. (2012) O espaço como palavra-chave. GEOgraphia v.14, n.28, p 8-39.

KAYSER, B. (1973) El espacio rural y el nuevo sistema de relaciones ciudad-campo. Revista de Geografía, Barcelona, v. VI, p. 209-17.

(1990) L' espace non-metropolisé du territoire français. In: KAYSER, B. et al. Géographie. Entre espace et developpement. Toulouse: Presses Universitaires du Mirai, p. 45-50.

(1996) I/s ont choisi la campagne. Paris. Éditions de l’Aube.

KOSIK, K. (1976) Dialética do Concreto, 2a ed., São Paulo: Paz e Terra.

LEFEBVRE, H. (1978) De lo rural a lo urbano. 4. ed. Barcelona: Península.

(1980) La presencia y la ausencia. Contribuición a la teoria de las representaciones; Fondo de Cultura Economica, Mexico.

(1999) A revolução urbana. Belo Horizonte: UFMG.

(2008) A produção do espaço. Original: La production de l'espace.1991; 4e éd. Paris: Éditions Anthropos, 2000). Tradução: Doralice Barros Pereira e Sérgio Martins.

LENCIONI, S. (2008). Concentração e centralização das atividades urbanas: uma perspectiva multiescalar. Reflexões a partir do caso de São Paulo. Revista de Geografia Norte Grande, n. 29, pp. 7-20.

. (2013) Metropolização do espaço: processos e dinâmicas. In FERREIRA, A. RUA, J. MARAFON, G. SILVA, A. C. P. da (orgs.) Metropolização do espaço: gestão territorial e relações urbano-rurais. Rio de Janeiro: Consequência, p. 17-34.

. (2015) Metropolização do espaço e a constituição de megarregiões. In: FERREIRA, Álvaro et al (Org.). Desafios da metropolização do espaço. Consequência.

(2018) Totalidade E Tríades: Compreendendo O Pensamento De Lefebvre. In: Políticas públicas e territórios: onze estudos latino-americanos / María Rosa Carbonari [et al.]; coordinación general de Fania Fridman; Luciana Alem Gennari; Sandra Lencioni. - 1a ed. - Ciudad Autónoma de Buenos Aires: CLACSO. Libro digital, PDF.

MARAFON, G. J. (2014) Territorialidades, ruralidades e as relações campo-cidade. CAMPOTERRITÓRIO: revista de geografia agrária. Edição especial do XXI ENGA-2012, p. 1-13.

MARX, K. (2011) O 18 brumário de Luís Bonaparte; São Paulo: Editorial Boitempo. 
MASSEY, D. (2004) Filosofia e política da espacialidade: algumas considerações. Geographia - Ano 6, no. 12, Niterói, UFF, p.7-23.

. (2018) Pelo espaço: uma nova política da espacialidade. Rio de Janeiro: Bertrand Brasil.

OLIVEIRA, V. (2007) Repensando o rural sob o prisma das urbanidades, em Nova Friburgo; 2007; Tese (Doutorado em Geografia) - Universidade Federal Fluminense, Niterói, RJ.

POULLE, F.; GORGEU, Y. (1997) Essai sur l'urbanité rurale: cinq territoires ruraux, leurs sérments et leurs modes de gouvernèment Paris: Syros.

RUA, J. (2002) Urbanidades e Novas Ruralidades no Estado do Rio de Janeiro: Algumas Considerações Teóricas. In: MARAFON, Gláucio José; RIBEIRO, Marta Foeppel (Orgs.). Estudos de geografia fluminense. Rio de Janeiro: Infobook, p. 27-42.

. (2005) A ressignificação do rural e as relações cidade-campo: uma contribuição geográfica. Revista da Anpege, Fortaleza, ano 2, n. 2, pp. 45-66.

(2013) Urbanidade, urbanidades, urbanidades no rural: uma construção para melhor compreender a unicidade do espaço geográfico". In FERREIRA, Alvaro et al. (orgs.). Metropolização do espaço, gestão territorial e relações urbano rurais. Rio de Janeiro: Consequência, p. 383-408.

. (2015) O preço da terra e os megaprojetos como marcantes urbanidades no rural na fase atual de organização do espaço geográfico. In: Álvaro Ferreira; Joao Rua; Regina Célia De Mattos. (Org.). Desafios da metropolização do espaço. 1ed.rio de janeiro: editora consequência, v. 1, p. 389-420.

(2017) No estado do Rio de Janeiro. In: FERREIRA, Alvaro, RUA, João, MATTOS, Regina Célia de (Org.). O Espaço e a metropolização: cotidiano e ação. Rio de Janeiro: Consequência, p. 443-486.

(2019) Metropolização do espaço, urbanidades no rural e novas ruralidades. In: MARAFON, Glaucio José; CHELOTTI, Marcelo Cervo; PESSÔA, Vera Lúcia Salazar (Orgs.). Temas em Geografia Rural. 1. ed. - Rio de Janeiro: EdUERJ, p. 293-318.

SANTOS, M. (1994) Técnica, Espaço, Tempo. Globalização e meio técnico-científico informacional. São Paulo: HUCITEC. (1996) A Natureza do Espaço: técnica e tempo, razão e emoção. São Paulo: HUCITEC.

SIMONI, J. (2019) Múltiplas escalas de transformação nas relações urbano-rurais: o espaço rural friburguense e suas urbanidades impulsionadas pelas técnicas de informação e comunicação. Tese (doutorado) - Pontifícia Universidade Católica do Rio de Janeiro, Departamento de Geografia e Meio Ambiente.

SOUZA, M. L. (2019) O que é a Geografia Ambiental? Ambientes - Revista de Geografia e Ecologia Política. Volume 1, Número 1, p. 14-37. 